\title{
Evaluation of serum cortisol and growth hormone in type 2 diabetic subjects attending University of Maiduguri Teaching Hospital, Nigeria
}

\author{
Y. P. Mamza*1 ${ }^{1}$, A. E. Udoh ${ }^{2}$, M. H. Etukudo ${ }^{2}$ \\ ${ }^{1}$ (Department of Medical Laboratory Science, College of Medical Sciences University of Maiduguri Nigeria) \\ ${ }^{2}$ (Department of Medical Laboratory Science, Faculty of Allied Medical Sciences University of Calabar
}

Nigeria)

\begin{abstract}
Emerging data shows that type 2 diabetes is the commonest form of diabetes and the prevalence level is increasing at an alarming rate. Diabetogenic hormones play a role in the complications of diabetes mellitus.This study therefore is an attempt to evaluate the serum cortisol and GH in type 2 diabetic subjects. These hormones have the potential to exacerbate the diabetic condition if produced in inappropriate amounts. Samples from 105 confirmed type 2 diabetic subjects attending Metabolic Clinic of University of Maiduguri Teaching Hospital and 71 non diabetic volunteers of identical age-matched were analyzed for fasting blood sugar, growth hormone, cortisol, insulin. Plasma glucose was estimated by the enzymatic method (glucose oxidase). Cortisol, growth hormone and insulin were determined by enzyme linked immunosorbent assay (ELISA) method. The data generated was analyzed using statistical software SPSS version 16.0 and Microsoft excels 2007. All the results were expressed as mean \pm SEM. The study revealed that serum cortisol and insulin were significantly higher $(P<0.05)$ in type 2 diabetic subjects $(163.47 \pm 8.91 \mathrm{ng} / \mathrm{ml}$ and $13.60 \pm 1.47 \mu \mathrm{iu} / \mathrm{ml})$ compared to the non-diabetic controls $(94.14 \pm 4.97 \mathrm{ng} / \mathrm{ml})$ and $8.17 \pm 0.72 \mu \mathrm{iu} / \mathrm{ml})$ respectively. A significant inverse correlation was observed between cortisol and insulin. This is consistent with the activity of cortisol as a diabetogenic hormone. Over fourteen percent (14.3\%) of the diabetic subjects had abnormally high cortisol values. This would contribute to the diabetic condition in these patients. The mean growth hormone value was significantly lower in type 2 diabetics $(P<0.05)$ when compared to the control group $(0.42 \pm 0.06 \mathrm{ng} / \mathrm{ml}$ versus $0.84 \pm 0.22 \mathrm{ng} / \mathrm{ml}$ ). The mean BMI of the diabetic subjects was significantly higher than the mean for controls. Raised cortisol is a possible exacerbating factor in some cases of type 2 diabetes. These patients should be routinely screened for the hormone.
\end{abstract}

Keywords - Type 2 diabetes, cortisol, growth hormone, insulin, BMI

\section{Introduction}

Diabetes mellitus is a global health problem affecting all age-groups and is associated with high morbidity and mortality rate, due to involvement of major organs in this disease condition. The increasing incidence particularly in developing countries of Asia and Africa poses a serious public health problem because of the consequential impact and financial burden in patient treatment and management [1]

Type 2 diabetes, the most common type, is characterized by disorders of insulin resistance and insulin secretion, either of which may be the predominant feature. The important point here is that insulin secretion does not cease when the disease develops but may be inadequate for the purpose for which it is being secreted. There is usually too much carbohydrate to be metabolized for the amount of insulin present.

The development of type 2 diabetes passes through several stages in its natural history. The most important of these is impaired glucose tolerance (IGT) and this stage is a marker for identifying those at risk of developing diabetes. Patients with this marker are usually obese and /or hypertensive [2]. Obesity and hypertension, therefore, appear to be independent or interdependent determinants of IGT

In type 2 diabetes mellitus, insulin resistance is characterized by an inadequate or insufficient response of peripheral tissues to a given concentration of plasma insulin [3]. This syndrome is usually identified by an inappropriately high ratio of insulin to glucose concentration in the plasma. Insulin resistance caused by circulating insulin antagonists occurs predominantly in clinical conditions. Several hormones, for example, cortisol and growth hormone have insulin- antagonistic effects. During hypoglycemia, these hormones are secreted to restored blood glucose levels by stimulating glucose release from the liver and inhibiting glucose uptake in peripheral tissues. Elevated levels of these hormones can produce insulin resistance and hyperglycemia.

The effect of cortisol in the glucose and lipid metabolism is to a large extent opposite that of insulin. Hepatic glucose production is increased, while insulin stimulated glucose uptake in muscle and adipose tissue is impaired. High serum levels of cortisol of endogenous origin can cause insulin resistance and in diabetes 
patients, this can lead to a determination of glycemic control [4]. Cortisol alters blood glucose by affecting glucose transporters in peripheral tissues such as fat and skeletal muscle 15]. Thus, cortisol can contribute to elevated blood glucose levels due to inefficient uptake of glucose in the peripheral tissue.

Corttisol may play an important role in the development of type 2 diabetes, it is possible that even small increase in cortisol within the range of normal, may have a detrimental influence by worsening diabetes and increasing complications [6].

Growth hormone stimulates protein anabolism in many tissues. This effect reflects increased amino acid uptake, increased protein synthesis and decreased oxidation of proteins. In fat metabolism, GH enhances the utilization of fat by stimulating triglyceride breakdown and oxidation in adipocytes. In carbohydrate metabolism, GH is one of a battery of hormones that serves to maintain blood glucose within a normal range. GH is often said to have anti-insulin activity, because it suppresses the abilities of insulin to stimulate uptake of glucose in peripheral tissues and enhance glucose synthesis in the liver [7].

Studies have shown that high levels of cortisol and GH decrease metabolism of glucose and increase mobilization and metabolism of fats, which contribute to insulin resistance in type 2 diabetes. This study therefore is an attempt to evaluate the serum cortisol and GH in type 2 diabetic subjects attending University of Maiduguri Teaching Hospital.

\section{MATERIALS AND METHODS}

A total of 105 type 2 diabetic and 71 age-matched non diabetic subjects participated in the study. The study was approved by the joint ethical committee of University of Maiduguri Teaching Hospital/ University of Maiduguri. The subjects included for this study were confirmed type 2 diabetic subjects attending University of Maiduguri Teaching Hospital Metabolic Unit. Apparently healthy individuals who are non-diabetic were used as controls. Exclusion criteria were type 1 diabetics, use of medications that may affect GH or cortisol levels (e.g., estrogen, progesterone, and glucocorticoids) and Patients that were depending on insulin for their treatment.

Samples were collected in Maiduguri in North- eastern Nigeria. Analysis of the samples was performed in the Chemical Pathology Laboratory, University of Calabar Teaching Hospital, Nigeria. Blood samples were collected in the morning from the subjects after an overnight fasting. A $5 \mathrm{ml}$ syringe and needle was used to collect $5 \mathrm{mls}$ of blood sample from the subjects. Two mls of the blood sample were taken into fluoride oxalate containers for fasting blood sugar (FBS) estimation, while $3 \mathrm{mls}$ were taken into a plain container for insulin, cortisol, and growth hormone analysis.

The serum samples were transported in a frozen state, in insulated packaging, along with frozen gel packs. The gel packs and the serum samples were placed in an ultra low temperature laboratory refrigerator at $860 \mathrm{c}$ for 48 hours prior to the transportation day. It was transported by road to Calabar, Nigeria within 24hours.

The biochemical parameters that were measured in this study included fasting blood sugar (FBS), serum insulin, cortisol and human growth hormone (hGH). Plasma glucose was estimated by the glucose oxidase method [8]. The reagent kit was obtained from RANDOX laboratories limited. Ardmore, Diamond Road, United Kingdom. Serum insulin was determined by the DRG insulin enzyme immunoassay method [9]. It was obtained from DRG international Inc. USA. Serum cortisol was determined by the DRG cortisol enzyme immunoassay method [10]. It was obtained from DRG international Inc. USA. Serum human growth hormone was determined by the DRG human growth hormone (hGH) immunoassay method [11]. It was obtained from DRG international Inc USA.

The data generated was analyzed using statistical software SPSS version 16.0. Students' t-test was used for analysis of differences between means for two groups. Pearson correlations were conducted to determine associations between different variables. A scatter plot graph was conducted using Microsoft excel 2007.The level of significance was set at $95 \%$, where p-value less than $0.05(\mathrm{P}<0.05)$ was considered as statistically significant. All the results were expressed as mean \pm SEM.

\section{RESULTS}

The total number of study subjects were one hundred and seventy six (176) as presented in table 1 . One hundred and five (105) were type 2 diabetics of which $42(40 \%)$ were males and $63(60 \%)$ were females. Seventy one (71) were controls of which $40(56.3 \%)$ were male and $31(43.7 \%)$ were females. Table 1 also shows the comparison of means of demographic variables between type 2 diabetics and control subjects. The mean systolic blood pressure, diastolic blood pressure and body mass index were significantly $(\mathrm{p}<0.05)$ higher in type 2 diabetic subjects when compared to the control subjects. There was no significant difference in the mean age of type 2 diabetics and the control subjects ( $p>0.05)$.

Table 2 shows a comparison of means of biochemical parameters in type 2 diabetics and control subjects. The mean fasting blood sugar, cortisol and insulin were significantly $(\mathrm{p}<0.05)$ higher in type 2 diabetics as compared to the control subjects. The mean growth hormone was significantly $(p<0.05)$ lower in type 2 diabetics as compared to the control group. 
Table 3 shows the percentage of subjects with abnormal biochemical parameters among type 2 diabetics and control subjects. Fifteen type 2 diabetics, $(14.3 \%)$ were found with abnormally high cortisol level above the upper reference limit (> $230 \mathrm{ng} / \mathrm{ml})$. The control group had none that was so abnormally high. There was no abnormally high growth hormone above the upper reference limit $(>7 \mathrm{ng} / \mathrm{ml})$ in type 2 diabetic subjects. However $2(1.4 \%)$ of control subjects had abnormally high GH. Eleven (10.5\%) of type 2 diabetics had insulin above the upper reference range $(>25 \mu \mathrm{iu} / \mathrm{ml})$, but the control group had only one $(1.4 \%)$ of such.

Figures 1-2 show correlation plots between cortisol and insulin; cortisol and GH respectively. There was a significant $(\mathrm{r}=-0.327 ; \mathrm{p}<0.05)$ negative correlation between cortisol and insulin. No significant correlation was found between cortisol and GH.

TABLE 1

Comparison of means of demographic variables in type 2 diabetic and control subjects

\begin{tabular}{lllll}
\hline Characteristic & $\begin{array}{l}\text { Type 2 diabetic } \\
\text { Subjects } \\
\mathbf{n = 1 0 5}\end{array}$ & $\begin{array}{l}\text { Control subjects } \\
\mathbf{n = 7 1}\end{array}$ & P-value & Remarks \\
\hline No. of males (\%) & $42(40 \%)$ & $40(56.3 \%)$ & - & - \\
No. of females (\%) & $63(60 \%)$ & $31(43.7 \%)$ & - & - \\
Age (years) & $49.79 \pm 0.71$ & $50.20 \pm 0.80$ & $>0.05$ & $\mathrm{NS}$ \\
Systolic Bp (mmHg) & $141.90 \pm 2.08$ & $117.46 \pm 1.56$ & $<0.05$ & $\mathrm{~S}$ \\
Diastolic Bp (mmHg) & $96.38 \pm 1.33$ & $81.66 \pm 1.08$ & $<0.05$ & $\mathrm{~S}$ \\
BMI $\left(\mathbf{k g} / \mathbf{m}^{\mathbf{2}}\right)$ & $26.88 \pm 0.45$ & $24.55 \pm 0.43$ & $<0.05$ & $\mathrm{~S}$ \\
\hline
\end{tabular}

Mean \pm SEM

TABLE 2

Comparison of means of biochemical parameters in type 2 diabetic and control subjects

\begin{tabular}{lllll}
\hline \multicolumn{1}{c}{ Biochemical } & $\begin{array}{l}\text { type 2 diabetic } \\
\text { Subjects } \\
\mathbf{n = 1 0 5}\end{array}$ & $\begin{array}{l}\text { Control subjects } \\
\mathbf{n = 7 1}\end{array}$ & P-value & Remarks \\
\hline FBS $(\mathbf{m m o l} / \mathbf{l})$ & $8.57^{ \pm} \pm_{0.33}$ & $4.48^{ \pm} 0.06$ & $<0.05$ & $\mathrm{~S}$ \\
GH $(\mathbf{n g} / \mathbf{m l})$ & $0.42 \pm 0.06$ & $0.84 \pm 0.22$ & $<0.05$ & $\mathrm{~S}$ \\
Cortisol $(\mathbf{n g} / \mathbf{m l})$ & $163.47 \pm 8.91$ & $94.14 \pm 4.97$ & $<0.05$ & $\mathrm{~S}$ \\
Insulin $(\boldsymbol{\mu i u} / \mathbf{m l})$ & $13.60 \pm 1.47$ & $8.17 \pm 0.72$ & $<0.05$ & $\mathrm{~S}$ \\
\hline
\end{tabular}
Mean \pm SEM

TABLE 3

Percentage (\%) comparison of abnormal biochemical parameters in type 2 diabetic and Control subjects

\begin{tabular}{lll}
\hline Biochemical parameters & $\begin{array}{c}\text { Type 2 diabetic subjects } \\
\mathbf{n = 1 0 5}\end{array}$ & $\begin{array}{l}\text { Control subjects } \\
\mathbf{n}=\mathbf{7 1}\end{array}$ \\
\hline Cortisol,>230(ng/ml) & $15(14.3 \%)$ & $0(0 \%)$ \\
GH, $\mathbf{7}(\mathbf{n g} / \mathbf{m l})$ & $0(0 \%)$ & $2(1.4 \%)$ \\
Insulin, $>\mathbf{2 5}(\boldsymbol{\mu i u} / \mathbf{m l})$ & $11(10.5 \%)$ & $1(1.4 \%)$ \\
\hline
\end{tabular}

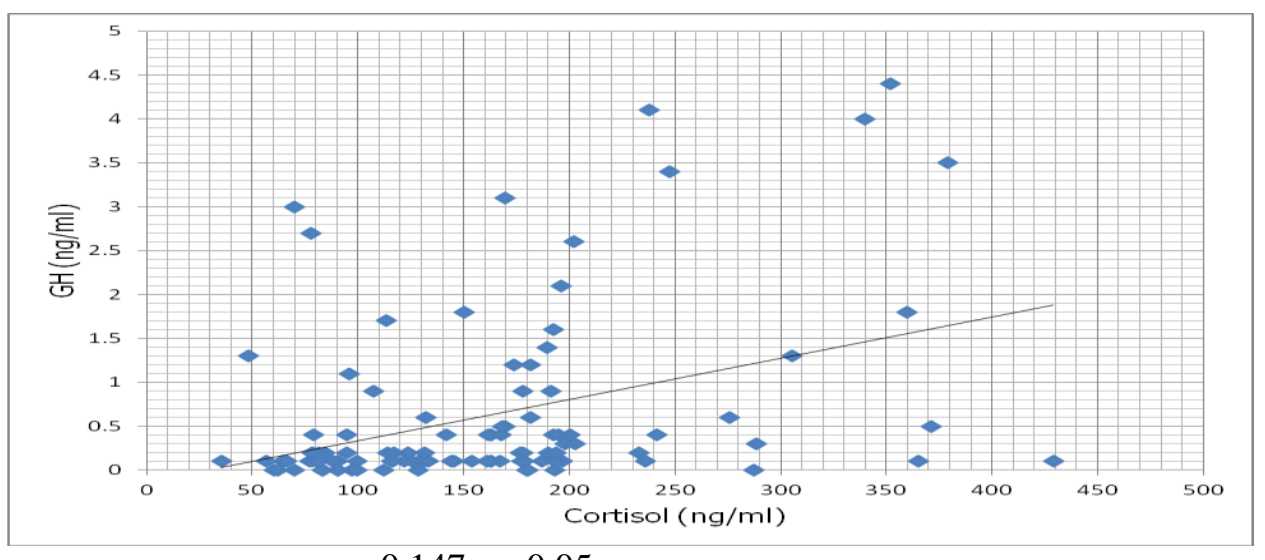

$r=0.147, p>0.05$

Fig. 1: Correlation plot between cortisol and GH in type 2 diabetic subjects 


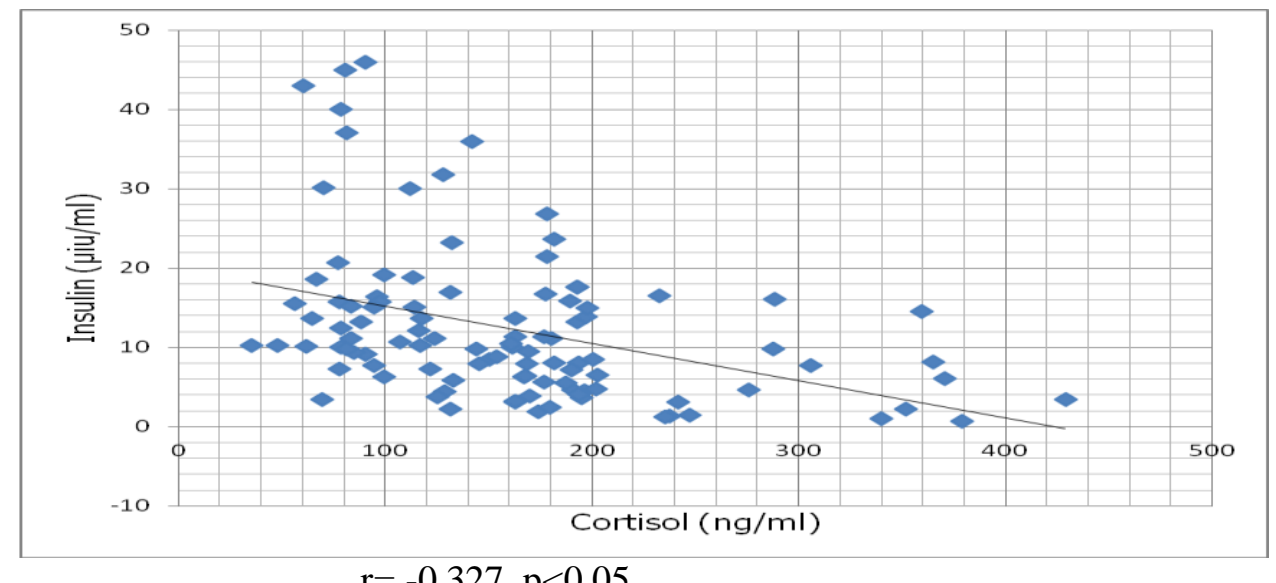

Fig. 2: Correlation plot between cortisol and insulin in type 2 diabetic subjects

\section{Discussion}

This work examined the degree of involvement of some diabetogenic hormones in the complications of diabetes millitus. Cortisol, and growth hormone were the hormones examined.

Cortisol was found at significantly higher $(\mathrm{p}<0.05)$ concentration in the sera of type 2 diabetics when compared with controls. Fifteen (14.3\%) of diabetic subjects had abnormally high serum cortisol level (greater than the upper reference limit of the reference range. Elevated cortisol induces hyperglycemia. The value found in this study may be a contributor to the diabetic condition. Elevated cortisol is associated with increase in hepatic gluconeogenesis and glycogenolysis and consequently with hyperglycemia. Cortisol is a glucocorticoid, the function of which is to ensure that blood glucose level remains elevated. Its role in diabetes mellitus may however be undesirable as it turns to sustain hyperglycemia. This finding points to the need to measure this hormone in diabetics as part of monitoring and control.

Cortisol alters blood glucose by affecting glucose transporters in peripheral tissues such as fat and skeletal muscle [12]. Thus cortisol can contribute to elevated blood glucose levels due to inefficient uptake of glucose in the peripheral tissues. It is possible that even small increases in cortisol levels, within the normal range may have a detrimental influence by worsening diabetic condition and increasing complications [6]. Cortisol has also been linked to obesity [13]. It stimulates hepatic triglycerides synthesis [14], increases the number of adipocytes in the visceral depots and stimulates appetite and hence obesity [15]. It also induces insulin resistance probably by antagonizing the antilipolytic effect of insulin [16].

In this study, a significant inverse association was observed between cortisol and insulin in type 2 diabetes. Higher cortisol concentrations are related to reduced insulin secretion and activity. This finding was also consistent with the in vivo and invitro studies of Mervat et al [17], which showed that glucocorticoids regulate insulin secretion.

The mean serum growth hormone level of our type 2 diabetics was lower than those of none-diabetic controls. These findings were similar to that of Kjeidsen et al [18] and Zoe et al [ 19], who in a separate studies reported reduced basal GH concentrations in type 2 diabetics. Elevated cortisol as we have already discussed above inhibit the release of GH by stimulating the release of somatostatin (a growth hormone antagonist [20]. It may also directly inhibit growth hormone effects at target tissues by inhibiting insulin-like factor-1 and other growth factors [21]. There is also clinical [22] and experimental [23] evidence suggesting an important role for insulin as a direct inhibitor of GH secretion. Thus the decrease in GH level in these diabetic subjects may be due to the elevated plasma cortisol and insulin level observed in these diabetics.

In this work, plasma insulin was significantly $(\mathrm{p}<0.05)$ higher in type 2 diabetic subjects as compared to the controls. The pancreas secrets insulin to remove excess glucose from the blood into the cells, where it is used to produce energy. Overtime however, the cells lose the ability to respond to insulin. The pancreas responds by pumping out even more insulin in an effort to get glucose into the cells, and this is the genesis of insulin resistance. Insulin resistance is an important component in the pathogenesis of type 2 diabetes [24]. The body attempts to compensate for this by increasing the production in the $\square$-cells and this leads to hyperinsulinemia. During glucoregulation, insulin lowers blood glucose by stimulating peripheral glucose uptake as well as inhibiting gluconeogenesis and glycogenolysis [25].

\section{Conclusion}

In conclusion, this study has found abnormally raised level of serum cortisol and significantly lower GH in type 2 diabetic subjects. Elevated cortisol is known to inhibit the release of GH by stimulating the release 
of somatostatin (a growth hormone antagonist). Our diabetic subjects had elevated BMI and high serum cortisol, both of which may be responsible for the reduced growth hormone status. The type 2 diabetics had significantly higher insulin levels than controls.

\section{Acknowledgements}

We are grateful to the Department of Chemical Pathology, University of Calabar Teaching Hospital for providing the facilities we needed for our analysis. The WHO unit in the University of Maiduguri Teaching Hospital deserves our appreciations for providing us with facilities needed for the storage and transportation of our samples to Calabar.

\section{REFERENCES}

[1] World Health Organization (2005). Prevalence of blindness from diabetes mellitus. Retrieved July 25, 2011 http://www.who.int/blindness/prevention of blindness from diabetes mellitus-with-cover-small. Pdf

[2] Owusu, S. K. (2002). Type 2 diabetes: are we missing the substance and chasing the shadow. Diabetes international, 12 (1), 3

[3] Harrihar, A., Pershadsingh, R., Lyle, C., \& Jay, M. M. (1986). Cellular mechanism of insulin action: implications for insulin resistance and type 2 diabetes mellitus. Journal of the American Association of Clinical Chemistry, 32 (10b), 819-822

[4] Olefsky, J. M. \& Kimmerling, G.(1976) Effects of glucocorticoids on carbohydrate metabolism. American Journal of Medical Science, 271: 202-210

[5] Orskov, L., Schmitz, O. \& Bak, J. F. (2001). Skeletal Muscle glucose uptake, glycogen synthase activity and Glu T4 content during hypoglycemia in type 1 diabetic subjects. Scand Journal of Clinical Laboratory and Investigation, 61 (5), 371-381

[6] Tracey, L. (2010). The role of cortisol and abdominal obesity in the epidemic of type 2 diabetes. Retrieved July 21,2011 from http://www.kon.org/urc/v9/liebman.html

[7] Bowen, R. (2006). Growth hormone (somatotropin). $\quad$ Retrieved $14 \quad$ July $2011 \quad$ from

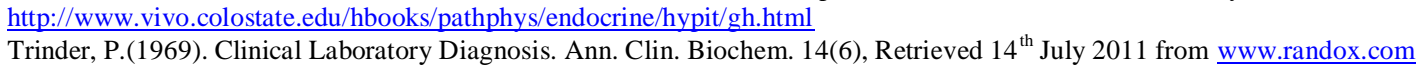

[8] Trinder, P.(1969). Clinical Laboratory Diagnosis. Ann. Clin. Biochem. 14(6), Retrieved $14^{\text {th }}$ July 2011 from www.randox.com
[9] Starr, J., Mako, M. E., Juhn, D. \& Rubenstein, A. H. (1978). Measurement of serum proinsulin-like material: Crossreactivity of porcine and human proinsulin in the insulin radioimmunoassay. Journal of Laboratory \& Clinical Medicine, 91 (4), 691-692

[10] Tietz, N. W. (1995). Clinical guide to laboratory test $\left(3^{\text {rd }}\right.$ ed). Philaldelphia: W. B. Saunders, 56-57

[11] Reiter, E. O., Morris, A. H. \& Gillivary, M. H. (1988). Variable estimates of serum growth hormone concentrations by different radioassay systems. Journal of Clinical Endocrinology \& metabolism, 66, 68-71

[12] Mathews, D. R., Hosker, J. P., Rudenski, A. S., Naylor, B. A., \& Turner, R. C. (1985). Homeostasis model assessment: Insulin resistance and $\beta$-cell function from fasting plasma glucose and insulin concentrations in man. Diabetologia, 28, 412-419

[13] Weststrate, J. A., Dekker, J., Stoel, M. \& Hautvast, J. G. (1990). Resting energy expenditure in women: Impact of obesity and blood fat distribution. Metabolism, 39, 11-17

[14] Klausner, H. \& Heimberg, M. (1967). Effect of adrenal-cortical hormones on release of triglycerides and glucose by liver. American Journal of Physiology, 212, 1236-1246

[15] King, B. M., Banta, A. B., Tharel, G. N., Bruce, B. L. \& Frohman, L. A. (1999). Hypothalamic Hyperinsulinemia and obesity: role of adrenal glucocorticoids. American Journal of Physiology, 245, 194-199

[16] Cigolini, M. \& Smith, U. (1979). Human adipose tissue in culture viii. Studies on the insulin antagonistic effect of glucocorticoids. Metabolism, 28, 502-510

[17] Mervat, M., El-Eshmawy, Asmaa, H., Azza, A. (2011). Relationship between IGF-1 and cortisol / DHEA-S Ratio in adult men with diabetic metabolic syndrome versus non-diabetic metabolic syndrome. Journal of Clinical Endocrinology and Metabolism, 1 (4), 13

[18] Kjeldsen, H., Hansen, A. P., Lundback, K. (1975). Twenty four hour serum growth hormone levels in maturity onset diabetes Diabetes, 24, 977-982

[19] Zoe, S. E., Juliana, C. N., Vincent, T. F., Chun-Chung, C. \& Julian, A. J. (1999). Plasma insulin, growth hormone, cortisol, and central obesity among Chinese type 2 diabetic patients. Diabetes care, 22, 1450-1457

[20] Rzaza, J., Massoud, A.F., Hindmarsh, P.C., Robinson, I.C. \& Brook, C.G.(1998). Direct effects of corticotrophin-releasing hormone on stimulated growth hormone secretion. Clinical Endocrinology, 48, 217-222

[21] Unterman, T.G., \& Philips, L. S.(1985) Glucocorticoid effects on somatomedin and somatomedin inhibitors. Journal of Clinical Endocrinology and Metabolism, 61, 618-625

[22] Lanzi, R., Maanzoni, M.E. \& Andreoti, A.C. (1997). Evidence for an inhibitory effect of physiological levels of insulin on the growth hormone $(\mathrm{GH})$ response to $\mathrm{GH}-\mathrm{releasing}$ hormone in healthy subjects. The journal of clinical Endocrinology \&metabolism, 82 (7), 2239-2243

[23] Melmed,S(1984).Insulin suppresses growth hormone secretion by rat pituitary cells. Journal of Clinical Investigation, 73 (5), 14251433

[24] William, T. (2011). Insulin resistance: Cellular and clinical concepts. Exp Bio Med, 228 (1), 13-26 . Retrieved 7 September, 2012 from http://ebm.rsmjournals.com/contents/226/1/13.pdf + html

[25] Randle, P. J., Garland P. B., Hales, C. N., Newsholme, E. A.(1963). Theglucose fatty acid cycle. Its role in insulin sensitivity and the metabolic disturbances of diabetes mellitus. Lancet1, 785-789 